\title{
USING REMOTELY SENSED DATA FOR DOCUMENTATION OF ARCHAEOLOGICAL SITES IN NORTHEASTERN MESOPOTAMIA
}

\author{
E. Matouškováa ${ }^{*}$, L. Starková ${ }^{\mathrm{b}}$, K. Pavelka ${ }^{\mathrm{a}}$, K. Nováček $^{\mathrm{c}}$, J. Šedina $^{\mathrm{a}}$, M. Faltýnová ${ }^{\mathrm{a}}$, E. Housarová a
}

\author{
${ }^{a}$ Czech Technical University in Prague, Faculty of Civil Engineering, Department of Geomatics, Thákurova 7, 166 29, Praha 6, \\ Czech Republic, eva.matouskova@fsv.cvut.cz \\ ${ }^{\mathrm{b}}$ University of West Bohemia, Faculty of Philosophy and Arts, Department of History, Sedláčkova 38, 306 14, Plzeň, Czech \\ Republic, lstarkov@kar.zcu.cz \\ ${ }^{c}$ Palacký University of Olomouc, Faculty of Arts, Department of History, Na Hradě 5, 771 80, Olomouc, Czech Republic, \\ karel.novacek@upol.cz
}

\section{Commission V, WG V/2}

KEY WORDS: Mesopotamia, Archaeology, MULINEM, Remote Sensing, Arbíl, Makhmúr al-Quadíma, Al-Hadítha

\begin{abstract}
:
This paper introduces two archaeological sites documented during the MULINEM (The Medieval Urban Landscape in Northeastern Mesopotamia) project. This project investigates the Late Sasanian and Islamic urban network in the land of Erbil, a historic province of Hidyab (Adiabene) that is located in northern Iraq. The investigated sites are the two deserted cities of Makhmúr al-Quadíma and Al-Hadítha. It is assumed that these two sites used to form large cities with high business and cultural importance in the medieval period. The archaeological locations are endangered by various threats. The Al-Hadítha site seems to be under the control of the „Islamic state“ at the moment and Makhmúr al-Quadíma is located just next to the town of new Makhmúr that expands rapidly and without complex urban plans. Documentation of the archaeological sites has been done by using remotely sensed methods together with in-situ measurements (where available). FORMOSAT-2 data that has been gained through a research announcement: Free FORMOSAT-2 satellite imagery and when combined with other sources (recent and historical data) it provides a powerful documentation tool. In-situ RPAS measurements and a DTM creation furnish a new source of highly valuable information. Influence of the political and security situation in Al-Haditha will be analysed.
\end{abstract}

\section{INTRODUCTION}

\subsection{The MULINEM project}

The MULINEM (The Medieval Urban Landscape in North eastern Mesopotamia) project is aiming to investigate the Late Sasanian and Islamic urban network in the land of Arbíl, historic province of Hidyab (Adiabene) that is located in northern Iraq. The research of the hierarchical urban network in a defined area belongs to approaches rarely used in the study of the Islamic urbanism. The project focuses on the cluster of urban sites of the 6 th -17 th centuries A.D. in Adiabene, northeastern Mesopotamia. The urban landscape, once a constituent of the prosperous Sasanian province and later becoming a part of the hinterland of the 'Abbasid megalopolis of Sāmarrā, eventually collapsed during the Ottoman era. The archaeological substance of the cities (ca. eighteen of them have been identified, see Figure 1) is largely in a very good state of preservation. The interpretation will concentrate on the issues of continuity of the ,Islamic' urban network, its dynamism and resilience to the political and economic changes. The social structure reflected in the built environment of individual cities will also be the focus. The project aims to reconsider some widely accepted models of the Islamic town development based on the comparative material coming mostly from Syropalestine. The implementation of this multidisciplinary project will be reached by combination of three approaches: analysis of historical texts, remote sensing and archaeological survey. Historical texts are early Christian chronicles and the account of the Arab geographers. Remote sensed data has played an important role in the identification of sites and is a main tool for the general layout study of the abandoned cities. The fieldwork aims to verify town plans resulting from the satellite imagery analysis and to obtain detailed data concerning the architectural remains. More information about the project can be found at the project website (mulinem.net) and in manuscript Matoušková, 2015.

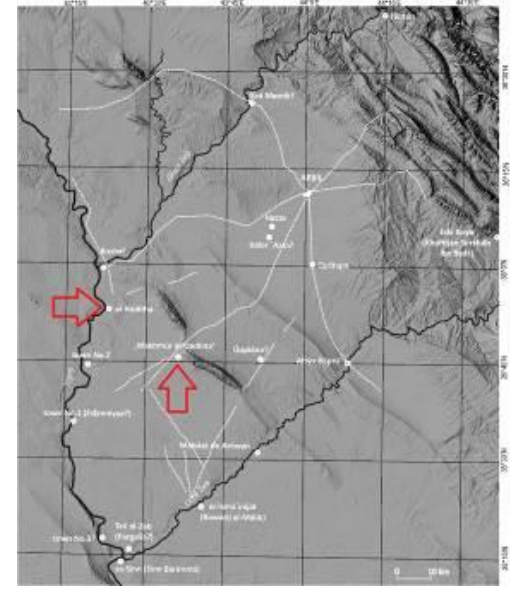

Figure 1 - Area of interest map as seen on Google Earth (a) and a closer view with detected historical sites (b) 


\subsection{Remote sensing for archaeology}

Remote sensing, particularly the analysis of satellite imagery, has appeared to be effective when documenting archaeological sites (Keeney, 2015; Lasaponara 2012). Satellite data imagery has become a powerful tool for historical sites documentation. (Menze, 2012; Mondino, 2012) Its main advantage is to have the possibility to analyse the site without actually visiting the area. This is especially important for unstable locations where in-situ measurements can lead to a serious safety risk for archaeologists and other people working on the site. Remote sensing methods cannot replace the fieldwork, but can give a fine picture about what is present on the historical site and can show the sites potential. With better resolution of recently launched satellites that goe up to several decimetres (QuickBird, GeoEye) a more detailed analysis can be performed and the amount of gained information rises. The benefit of remote sensing lies also in the opportunity of temporal analysis of the location of interest (Pavelka, 2012; Pavelka 2015), thus historical airborne/spaceborne data can be found in archives (e.g. USGS). The resolution of historical data is usually lower, so it is complicated to conduct a detailed analysis, but it is extremely useful for seeing the evolution of the specific historical site. The Czech Technical University in Prague, Faculty of Civil Engineering, department of Geomatics has experienced several projects where remote sensing was used for historical sites documentation. (Faltýnová, 2015; Pavelka, 2010; Matoušková, 2011; Matoušková, 2012).

The use of Remotely Piloted Aircraft Systems (RPAS) for archaeological purposes has become very popular. These methods provide fine images with spectral and spatial resolution depending on the flight height and sensor type that can be changed with respect to the location of interest. Czech Technical University, Faculty of Civil Engineering has already used RPAS devices for several projects (Šedina, 2015; Šedina, 2016) and the results have been found sufficient.

\section{DATA}

\subsection{CORONA}

The military CORONA system (operating from the 1960s to the beginning of the 1970s) that was driven by USGS is a great source of historical space borne data. It recorded the landscape before the recent, large-scale industrial changes and enable basic mapping of archaeological features. The earliest CORONA datasets possess the resolution about 12 meters, but since 1967 the resolution has improved up to about $1,8-2 \mathrm{~m}$ under ideal conditions. Most of the features detected on the CORONA system are quite impossible to observe in the medium resolution satellites which followed. Another big advantage of the later CORONA programme was the opportunity to work with a stereoscopic images. More information can be found on website http://space.jpl.nasa.gov/msl/Programs/corona.html

\subsection{FORMOSAT-2}

FORMOSAT-2 data that has been gained through a research announcement: Free FORMOSAT-2 satellite Imagery conducted by Centre for Space and Remote Sensing Research, National Central University. FORMOSAT was launched on 21. 5. 2004. Four multispectral bands (blue, green, red, NIR) with an $8 \mathrm{~m}$ resolution together with a panchromatic band with $2 \mathrm{~m}$ pixel give fine images suitable for archaeological purposes.
With the public tender, 10 images (four archive and six newly acquired images) of different archaeological sites of the Adiabene area were purchased. Full image size is 24 x $24 \mathrm{~km}$ and only sections of original data have been used. More information can be found on website http://www.nspo.org.tw/2008e/projects/project2/intro.htm

\subsection{Pleiades}

The Pleiades is a French administration Earth observing satellite constellation launched in 2011 that is used for civil and military applications. It is composed of two satellites (Pleiades 1A and 1B) each equipped with $70 \mathrm{~cm}$ resolution optical imaging device in visible and near-infrared spectrum. The revisit time can be as low as 24hours. Due to its stereoscopic cover capabilities it is widely used for creation of Digital Elevation Models (DEM). More information can be found

on website https://pleiades.cnes.fr/en/PLEIADES/index.htm

\subsection{RPAS}

A low cost Remotely Piloted Aircraft System (RPAS) named "the eBee" (see Figure 2) has been used for the Machmúr alQuadíma archaeological site documentation. The eBee (a good price-performance ratio for basic university research) drone consists of a styropor airframe, with an electrically powered engine with a pusher propeller, battery $(1850 \mathrm{~mA}$ and $2100 \mathrm{~mA}$ ), GNSS and IMU unit, digital camera, radio-modem and control system. For flight control, an ordinary notebook computer with special software is used. With this software it is possible to easily manage all the necessary project information like area (based on free Google maps and other maps or orthophotos), pixel resolution, image overlapping, flight time, distances etc. The typical flight altitude is 100 $200 \mathrm{~m}$, with a flight time of up to 40 minutes and typical documented area of approximately $1 \mathrm{sqr} \mathrm{km}$; pixel size or so called Ground Sample Distance (GSD) can be set and reaches normally 3-6 cm (with small compact Canon camera 16MPix; there are two possibilities - one classic camera for visible spectral range (Canon IXUS 127 HS) and one modified camera for near infrared range (Canon ELPH 110 HS). More information can be found on https://www.sensefly.com/drones/ebee.html. Primary outputs from a set of taken photos (typically hundreds of photos) are digital surface models (DSM) and orthophotos. Data processing to an orthophoto and DSM can be done using additional software. Agisoft Photoscan software has been used in this case.

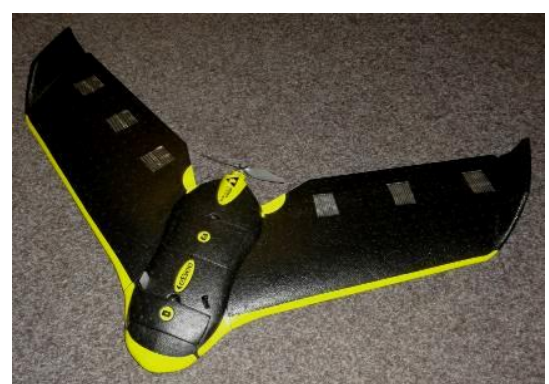

Figure 2 - RPAS - "The eBee"

This survey was conducted in November 2015 by the MULINEM team. Due to the nature of RPAS documentation many permissions and documents had to be approved since the 
area of interest has been located in a secured area close to territory of the so-called Islamic state.

\section{AL-HADÍTHA (HADÍTHAT AL-MAWSIL)}

\subsection{Site introduction}

Hadithat used to be the most important city in the Central Tigris region, situated on a vital thoroughfare connecting Baghdad and Mosul. The city was founded during the Sasanian Period, bore the name Naw Gird („New Town“) but lost its urban status in the late 6th century AD. During the Umayyad Period, the city was re-founded under the definitive name and witnessed a period of maximal prosperity in the 9th and 10th century. Then a slow process of the final decline commenced and the city was eventually abandoned within the 12th century. The remains of the unfortified city are preserved either in relief or in soil marks in a 3,0 km long and $0,79-1,33 \mathrm{~km}$ wide strip whose western limit is identical with the terrace edge of Tigris river, see Figure 3 . The minimal area, continuously covered by settlement traces, amounts 307,5 ha. Two areas in the centre of the site appear differently on the surface and this difference may be caused by use of more permanent material (likely baked bricks) then those in the rest of the site. These areas can be linked with monumental buildings known from other sources: with an Umayyad congregational mosque (B) and an episcopal church, founded in the beginning of the 7th century $\mathrm{AD}(\mathrm{C})$. In the NE part of the city, a very large residential compound left its traces (D), likely used as a residence of a high officer of caliphal army, less probably as a cantonmentblock. At least 12 quadrilateral fortified residences are visible in surrounding. South fringe of the site served as a large cemetery and the 'Abd Allāh Shrine was built here in the 13th century $\mathrm{AD}$, serving for centuries as an important site of pilgrimage until its demolition by ISIS in 2014 .

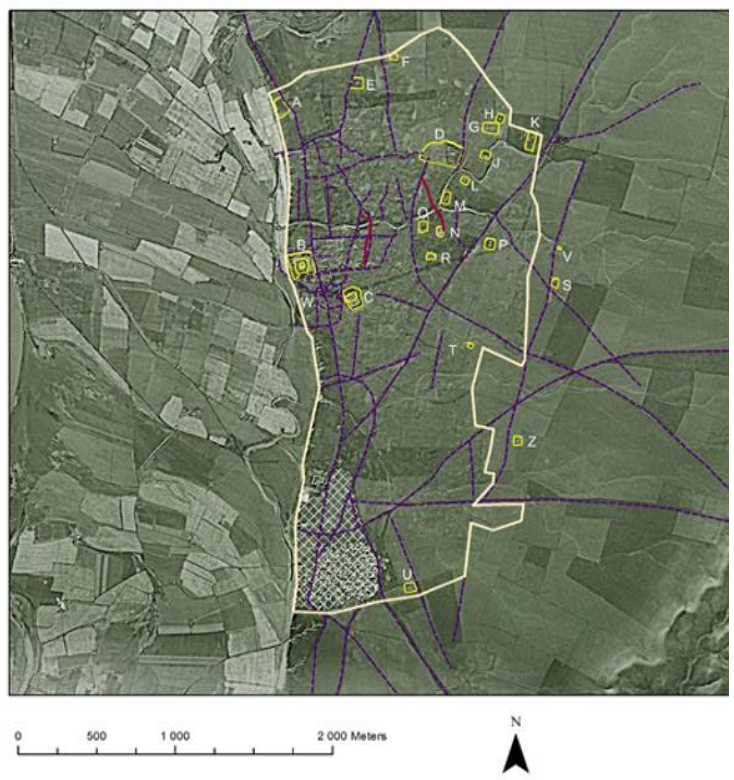

Figure 3 - Plan of Al-Hadítha archaeological site based on Hexagon (mission following CORONA) satellite imagery (acquired on 25. 2. 1972, mission 1202-2, GSD 0,6m)

\subsection{Results}

Due to the location of this archaeological site and the complicated security situation in this area (confrontation with so-called Islamic State) new in-situ measurements could not be performed in order not to expose the MULINEM team to security problems. This analysis is then based on archive and newly acquired satellite imagery. The CORONA system archive shows the image of the area of interest from mission KH4-B with resolution of 6 feet (appx. 1,83m). This image had been acquired on 16.8 .1968 (

Figure 4). Due to the previously mentioned research announcement new acquisition of FORMOSAT-2 satellite could be used. This area was documented on 24. 10. 2014 with an $8 \mathrm{~m}$ resolution in visible and near-infrared spectrum and $2 \mathrm{~m}$ in the panchromatic channel. A Gram-Schmidt spectral sharpening method has been found to be appropriate and therefore used in this case. Several other image processing steps like histogram stretching, reflectance transformation and layer stacking have been performed in order to obtain sufficient results. Satellite imagery has been compared with a vector layer that is based on previous remote sensing analysis. Similar vector layers have been used for all images (cemetery - yellow, city outline - red, features found on site - green, historic routes - blue). For better visualisation of results various band synthesis and filtering methods has been used.

\subsubsection{CORONA}

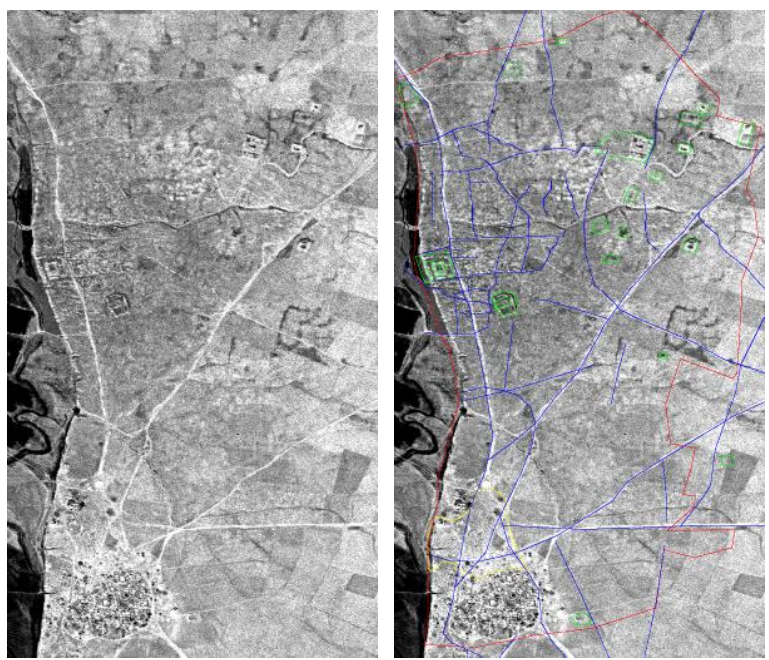

Figure 4 - Al-Hadítha as seen on CORONA image acquired on 16. 8.1968 with an overlaid objects of interest on the right picture (Cemetery - yellow, city outline - red, features found on site - green, historic routes - blue)

\subsubsection{FORMOSAT-2}

Band synthesis together with various image-processing methods (e.g. histogram stretching) can highlight objects of interest and show information hidden in the image.

Figure 5 shows synthesis of first three FORMOSAT-2 bands (RGB) and

Figure 6 displays bands 2, 3 and 4 (NIRGB) where vegetation is marked red. 

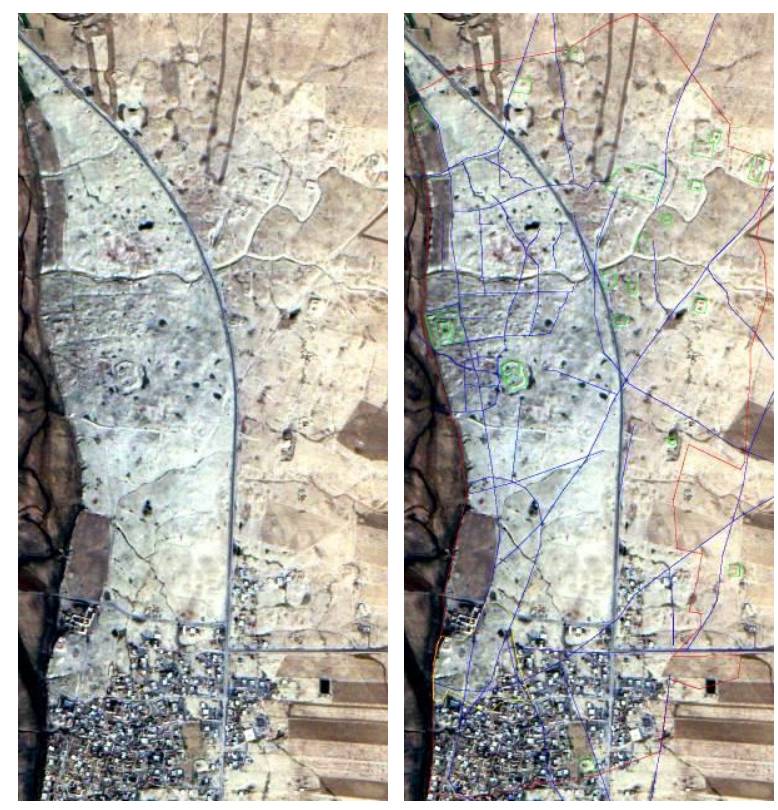

Figure 5 - Al-Hadítha - a RGB synthesis of the FORMOSAT2 image (acquired on 24. 10. 2014) with an overlaid objects of interest on the right picture (Cemetery - yellow, city outline red, features found on site - green, historic routes - blue).
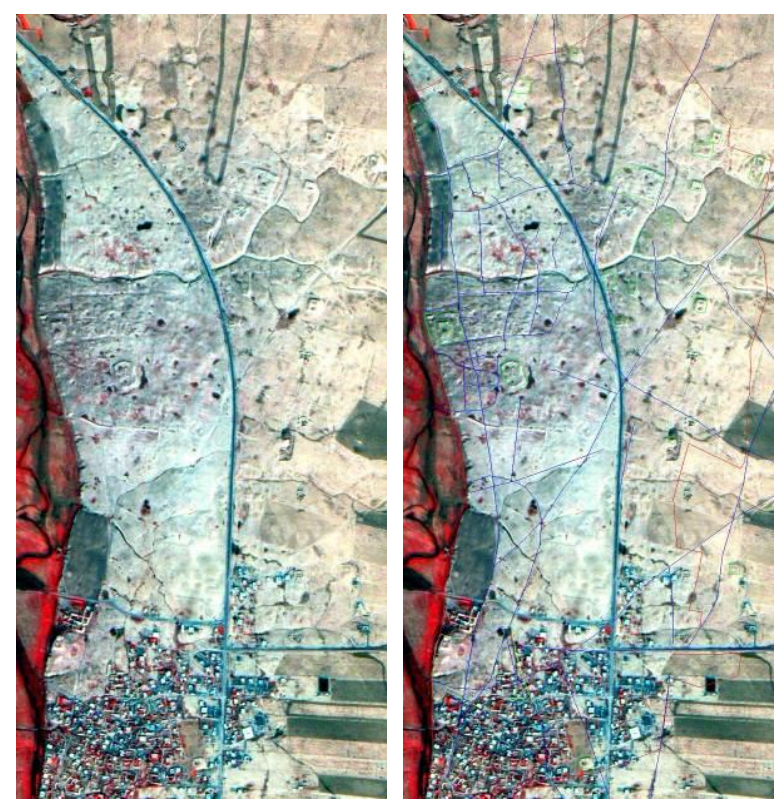

Figure 6 - a NIRGB synthesis of the FORMOSAT-2 image (acquired on 24. 10. 2014) with an overlaid objects of interest on the right picture (Cemetery - yellow, city outline - red,

features found on site - green, historic routes - blue).

If an object of interest is assumed as a line or is defined by sharp edges, filtering methods provide a powerful tool for its highlight. An example is shown on Figure 7.

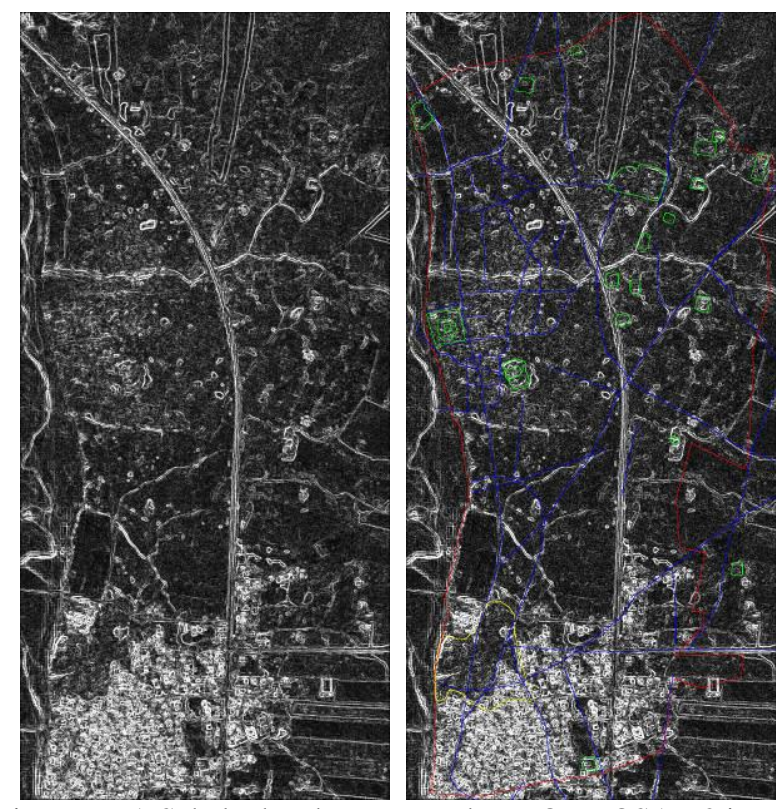

Figure 7 - A Sobel edge detector used on FORMOSAT-2 image of Al-Hadítha (acquired on 24. 10. 2014) with an overlaid objects of interest on the right picture.

\section{MACHMÚR AL-QUADÍMA}

\subsection{Site introduction}

The site was identified in the CORONA satellite imagery on the eastern outskirts of the current town of Makhmúr. The site is locally known as Makhmúr al-Qadíma (Fiey, 1965), but no mentions in the sources have been identified so far which might be connected with the site. The more than 100-hectarlarge site is lying in the non-cultivated landscape and is, therefore, perfectly visible in the relief, but the western part has been recently flattened due to town expansion and some areas on the south started to be cultivated few years ago. The probably non-fortified settlement area comprises several tens of low mounds, some of them are of big dimensions and of regular plans and seem to be arranged into a unified urban pattern (see Figure 8). An outstanding structure - a large square enclosure (ca. $120 \times 120 \mathrm{~m}$ ) consists of the 3-6 m high rampart - is located in the north part of the site (see Figure 9).

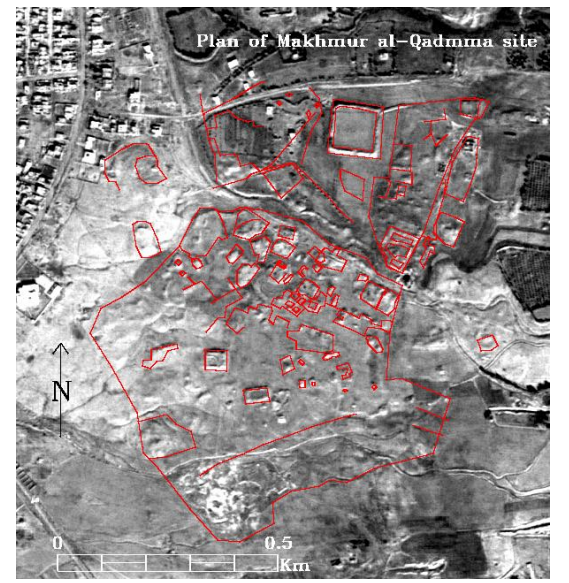

Figure 8 - Plan of Makhmúr al-Qadíma archaeological site based on FORMOSAT-2 band 1 


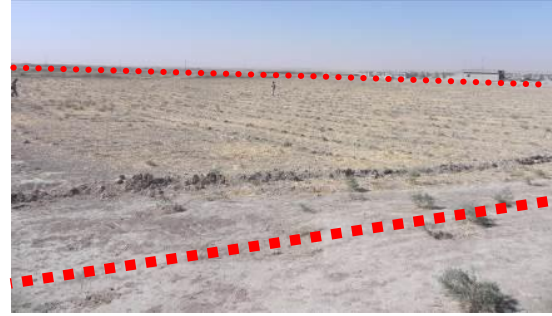

Figure 9 - A large square enclosure located in the northern part of the site as seen on site

Inside and in surroundings of the enclosure, only Sasanian pottery could be collected. South of the enclosure, two other square mounds are visible: both of them are remains of masoned building complexes (see Figure 10) from which the northern one is extremely well preserved under the rubble, apparently up until the level of the vaults.

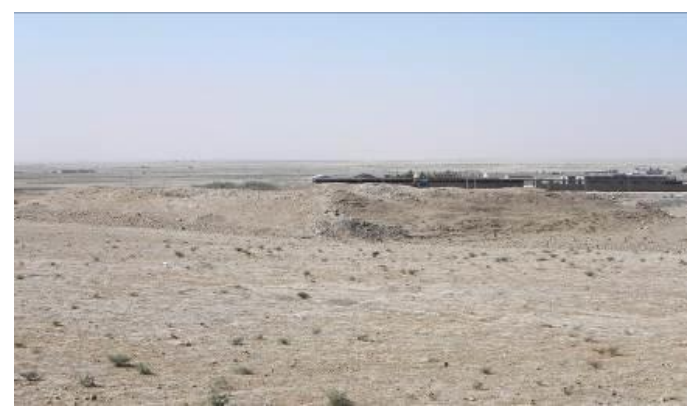

Figure 10 - Makhmúr al-Qadíma, the qasr from northeast

The regular plan of these complexes reminds us of the standardized Umayyad castles (qusur in Arabic, sg. qasr) in the Levant area; the remains are covered by scatters of Early Islamic pottery. Observations in the western, mostly flattened part of the site brought pottery indications of Uruk, NeoAssyrian and Parthian periods, which suggests a more complex settlement history of this important site. The possible central character of this site is indicated also by an occasional find of a large cluster of cemeteries in the mountainous valley behind the Bayz Agha Dezaye Tomb. The ca. 10 hectares large burial area (Figure 11) consists of one domed tomb and several thousands of grave stelae normally without any inscriptions or glyptic, which suggests an early dating of the site.

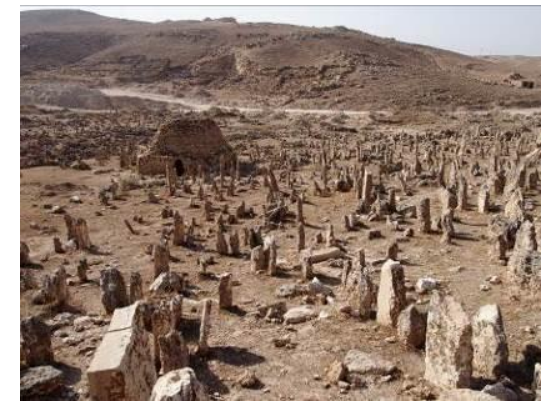

Figure 11 - Makhmúr al-Quadíma cemetery

\subsection{Results}

Satellite imagery has been processed in a similar way as for the Al-Hadítha archaeological site (see chapter 3.2). CORONA image acquisition date (16.8.1968, mission KH4-B) with 6 feet (appx. 1,83m) pixel resolution has been used (Figure 12). Analysed FORMOSAT-2 images were acquired on 2. 11. 2014 with $8 \mathrm{~m}$ resp. $2 \mathrm{~m}$ resolution. Identical band synthesis and filtering methods as mentioned in chapter 3.2.2. are shown below, see Figs 13 - 15.

Unlike the Al-Hadítha site that provides security risk for the MULINEM team, Makhmúr al-Qadíma is located not far (appx $60 \mathrm{~km}$ ) from the city of Arbíl, where the security situation is not so sharp. Due to this fact, an RPAS measurement together with additional in-situ surveys could be performed. An RPAS provides high-quality outcomes from which a Digital Elevation Model (DEM) and an orthophoto can be derived. Pleiades imagery and a derived DEM has been purchased in order to compare these results with RPAS deliverables.

\subsubsection{CORONA}
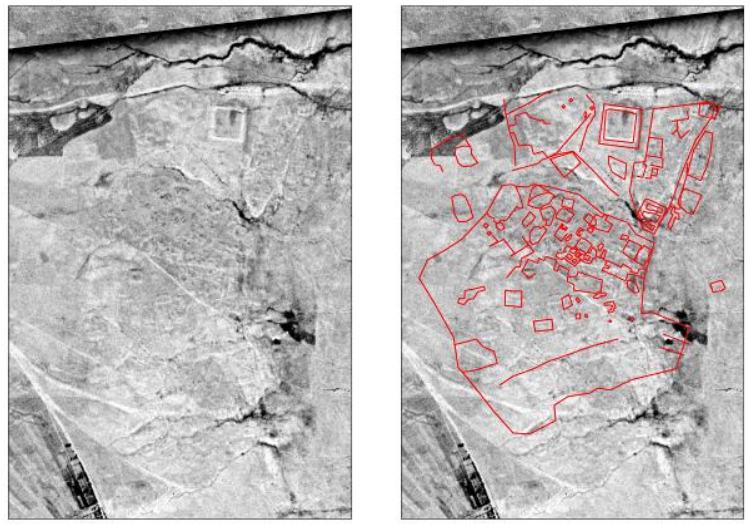

Figure 12 - Makhmúr al-Qadíma - CORONA (acquired on 16.8. 1968) with an overlaid objects of interest on the right picture

\subsubsection{FORMOSAT-2}
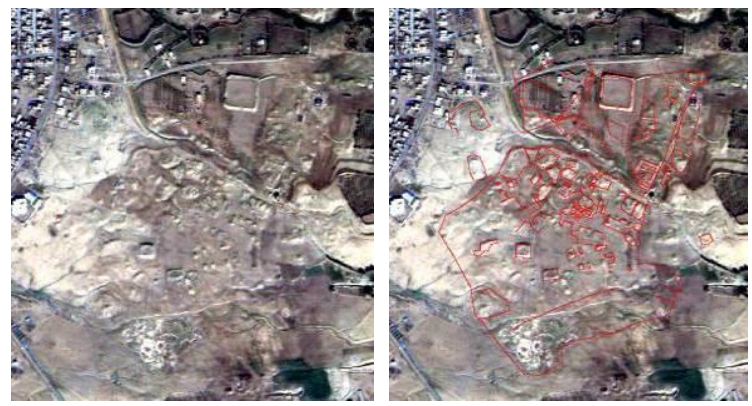

Figure 13 - Makhmúr al-Qadíma - a RGB synthesis of the FORMOSAT-2 images (acquired on 211.2014 ) with an overlaid objects of interest on the left picture.
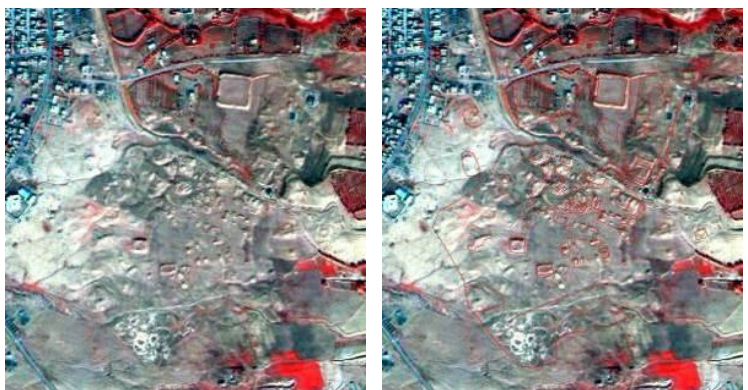

Figure 14 - Makhmúr al-Qadíma - a NIRGB synthesis of the FORMOSAT-2 images (acquired on 211.2014 ) with an overlaid objects of interest on the left picture 


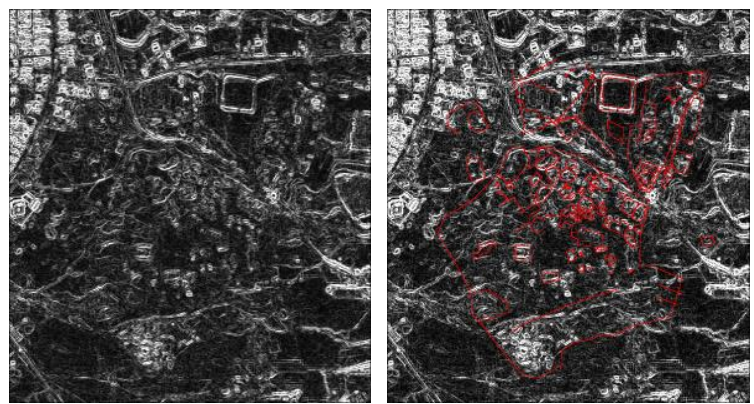

Figure 15 - A Sobel edge detector used on FORMOSAT-2 image of Makhmúr al-Qadíma site with overlaid objects of interest on the left picture

\subsubsection{Pleiades}

A Digital Elevation Model and an orthophoto derived from a set of stereoscopic images from the Pleiades satellite constellation has been purchased. These were further analysed and used for a comparison with RPAS outcomes.

\subsubsection{DEM}

A Digital Elevation Model (DEM) created from two archive images (acquisition dates - 12. 11. 2013 southern part and 10. 12. 2013 northern part) with resolution of $1 \mathrm{~m}$ (Figure 16) has been purchased.
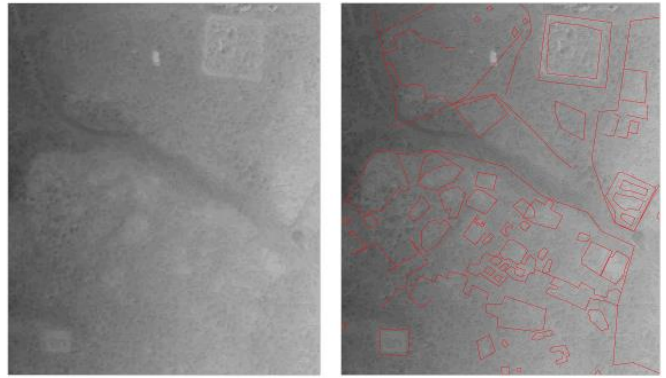

Figure 16 - A Digital Elevation Model (GSD 1m) derived from Pleiades stereoscopic image set of the Makhmúr al-Qadíma site with overlaid objects of interest on the right picture.
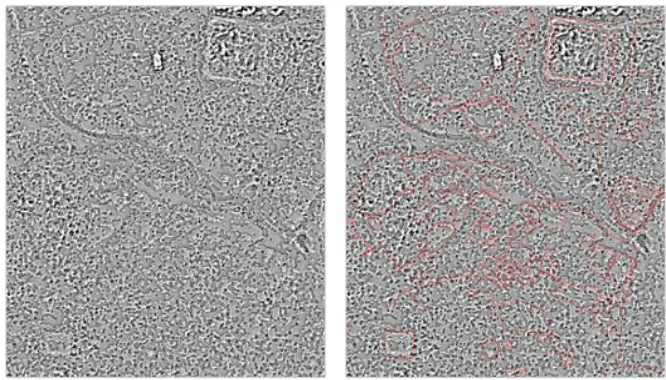

Figure 17 - A difference Digital Elevation Model (GSD 1m) derived from the Pleiades DEM of the Makhmúr al-Qadíma site with overlaid objects of interest on the right picture.

In order to highlight features of interest, a difference Digital Elevation Model (DDEM) has been created. For the DDEM, a smoothed DEM is needed. To derive a smoothed DEM a mask of previously defined parameters is set. This mask is then applied to every pixel of the original DEM and gives this pixel a new value by calculating the mask pixel average and a smoothened DEM is calculated. A Difference Digital Elevation
Model (DDEM - Figure 17) is then computed by subtracting the smoothened DEM from the original one. A mask size of 5pixels (corresponding to $5 \mathrm{~m}$ ) has been chosen. Processing has been done using ArcGIS software.

\subsubsection{Orthophoto}

An orthorectified image has been derived from the Pleiades dataset. Diverse band synthesis has been used to emphasise features of interest (Figure 18 and Figure 19). GSD of 0,5m has been achieved.
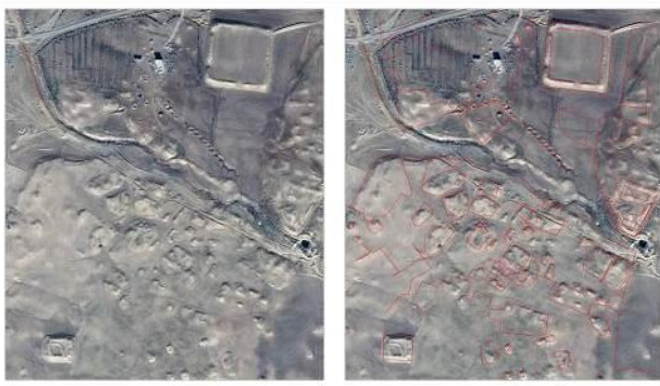

Figure 18 - Pleiades orthophoto of the Makhmúr al-Qadíma site with overlaid objects of interest on the right picture - RGB synthesis; GSD $0,5 \mathrm{~m}$
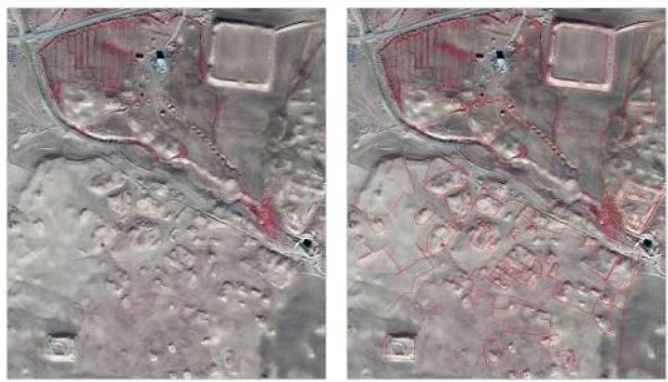

Figure 19 - Pleiades orthophoto of the Makhmúr al-Qadíma site with overlaid objects of interest on the right picture NIRGB synthesis, GSD 0,5m

\subsubsection{RPAS}

Similar approach as mentioned in chapter 4.2.3 has been used for processing the RPAS data. The dataset consists of 1181 images (548 NIR images with 5cm GSD, 97 VIS images with 3 $\mathrm{cm}$ GSD and 536 VIS images with $5 \mathrm{~cm}$ GSD) Images were purchased with minimum of $60 \%$ overlap. Data has been processed in Agisoft Photoscan and ArcGIS software.

\subsubsection{DEM}

A Digital Elevation Model has been created from the RPAS dataset (Figure 20) as well as the corresponding Difference Digital Elevation Model (Figure 21). Mask size has been set identical to Pleiades (chapter 4.2.3.1.) corresponding to $5 \mathrm{~m}$ that is defined using 25 pixels with resolution of $20 \mathrm{~cm}$. With this GSD many features of interest are visible. This data source provided complex view of the site to archaeologists and other specialists. In this case study they could operate with terrain elevation that helps the individual architecture reconstruction (in the centre part of the site, where were ruins of a destroyed monastery have been detected). 

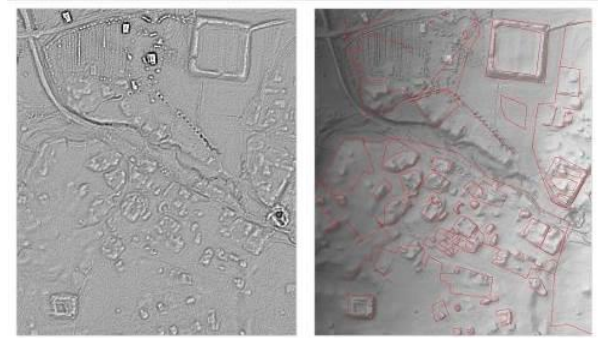

Figure 20 - A Digital Elevation Model (GSD 0,2m) derived from RPAS data set of the Makhmúr al-Qadima site with overlaid objects of interest on the right picture.
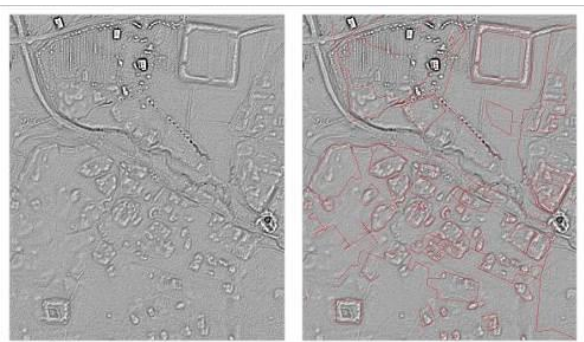

Figure 21 - A difference Digital Elevation Model (GSD 0,2m) derived from the RPAS DEM of the Makhmúr al-Qadima site with overlaid objects of interest on the right picture.

\subsubsection{Orthophoto}

An orthorectified image has been derived from the RPAS dataset, Fig. 22, 23. It provides a fine resolution of $10 \mathrm{~cm}$ and thus can serve as a reference image for archaeological applications. Even small features are clearly visible. The orthophoto provides new potential for individual features interpretation. Objects of interest that are difficult to detect from the terrain positions start to be more visible. This analysis increases the accuracy of resulting plans as well as street network maps.
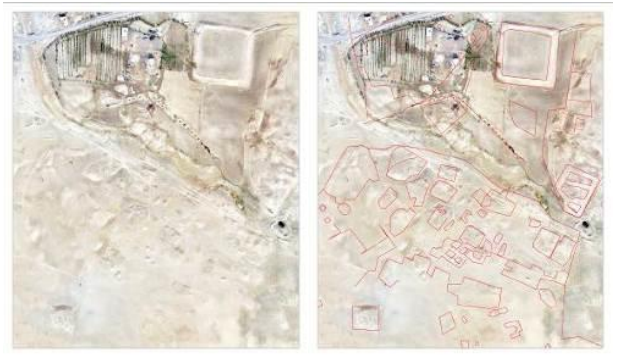

Figure 22 - RPAS orthophoto of the Makhmúr al-Qadima site with overlaid objects of interest on the right picture. - RGB synthesis; GSD 0,1m
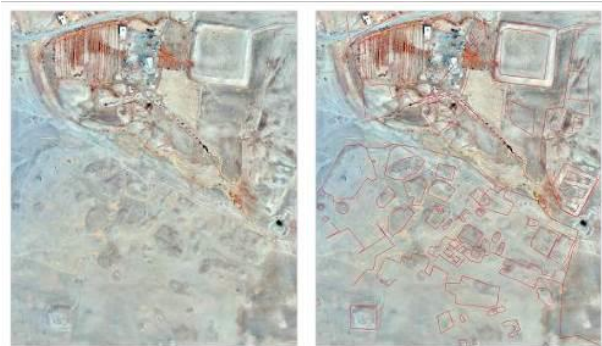

Figure 23 - RPAS orthophoto of the Makhmúr al-Qadima site with overlaid objects of interest on the right picture. NIRGB synthesis, GSD $0,5 \mathrm{~m}$

\section{CONCLUSIONS}

Various remote sensing methods has been used to document two archaeological sites in northern Iraq. FORMOSAT-2 images from new acquisition (2014), CORONA archive data together with DEM and orthophoto derived from Pleiades satellite constellation has been analysed and compared with RPAS in-situ survey.

It was found that FORMOSAT-2 images with several preprocessing and processing steps are suitable for remote sensing documentation of archaeological sites and provide sufficient level of detail. CORONA images have also been very useful. The power of historical data lies in the fact that new structures are created every day and very often hidden artefacts are not surveyed in advance and thus destroyed. With archive imagery we can see the surface as it used to be in the past. Preprocessing and processing methods were performed with Excelis ENVI software.

A comparison between an orthorectified image derived from FORMOSAT- 2 and RPAS data has been made. Figure 24 shows an overlay of FORMOSAT-2 data over RPAS orthophoto together with corresponding vector layers. A similarity transformation to 12 tie points has been made. The standard deviation of $1,44 \mathrm{~m}$ and transformation parameters (rotation $0,085^{\circ}$ and shift $-33,31 \mathrm{~m}$ in $\mathrm{X}$ axis and $-7,07 \mathrm{~m}$ in $\mathrm{Y}$ axis) has been calculated. Similarity transformations have been also used to compare orthophotos form Pleiades and RPAS with more (15) tie points thanks to better image resolution and this identification. This transformation had standard deviation of $0,72 \mathrm{~m}$ and parameters: rotation $0,003^{\circ}$; shift $1,85 \mathrm{~m}$ in $\mathrm{X}$ axis, $-0,24$ in $\mathrm{Y}$ axis.

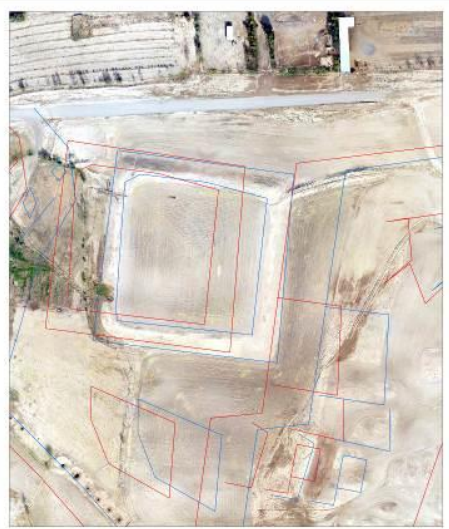

Figure 24 - RPAS orthophoto overlayed by FORMOSAT-2 orthorectified image, transformation parameters (rotation $0,085^{\circ}$ and shift $(33,310 \mathrm{~m}$ in $\mathrm{X}$ axis and $-7,067 \mathrm{~m}$ in $\mathrm{Y}$ axis), FORMOSAT- 2 in red and RPAS in blue

Digital elevation models have been compared using a Matlab software since RPAS and Pleiades do not share the same elevation system (RPAS elevation relates to ellipsoid and Pleiades relates to geoid). The resulting image can be seen on Figure 25. In order to obtain these results, a remoteness (elevation difference) for every pixel has been calculated. From this data an average value is computed $(9,52 \mathrm{~m}$ with standard deviation of $1,17 \mathrm{~m}$ ). This average value is then subtracted from remoteness and resulting value for every pixel is stored. RPAS orthophoto image is set as master in this workflow.

It has been demonstrated that RPAS survey provides very high resolution data and shifts remote sensing archaeological prospection into new age. With this level of detail $(10 \mathrm{~cm})$, even small features of interest become visible and can be then 
analysed on site. This method requires in-situ measurement and operators can face security risks in location with the complicated political situation as we see nowadays in northern Iraq.
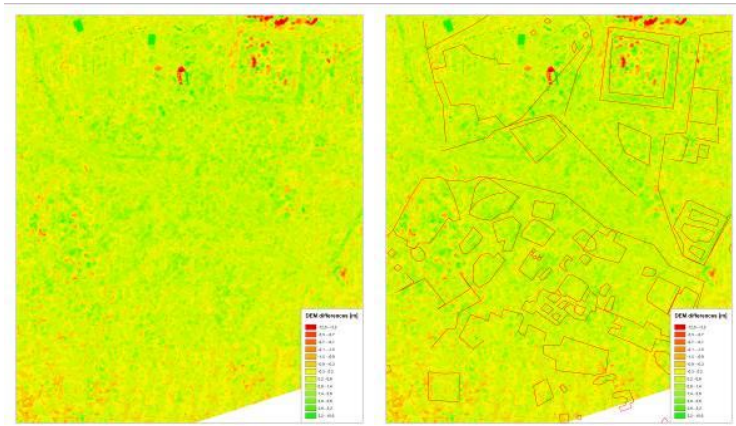

Figure 25 - DEM comparison with GSD of 1m (RPAS image has been set as a master)

Satellite remote sensing methods performs an irreplaceable role in documentation of archaeological sites located in politically unstable locations but cannot fully replace archaeological prospection on site. Thanks to satellite remotely sensed data it is possible to explore cultural heritage in desired areas without putting anyone at risk. Archaeological sites can be destroyed by local conflicts forever and it is highly necessary to document these extremely valuable cultural heritage sites for future generations.

\section{ACKNOWLEDGEMENTS}

The MULINEM (Medieval Urban Landscape in the Northeastern Mesopotamia) project is funded by the Czech Science Foundation.

\section{REFERENCES}

Faltýnová, M. - Pavelka, K. - Šedina, J. - Nový, P.: COMPLEX ARCHAEOLOGICAL PROSPECTION USING COMBINATION OF NONDESTRUCTIVE TECHNIQUES. In 25th International CIPA Symposium 2015 (XL-5/W7). Taipei: ISPRS, 2015, p. 141-146. ISSN 2194-9034.

Fiey, J. M. 1965: Assyrie chrétienne: Contribution à l'étude de l'histoire et de la géographie ecclésiastiques et monastiques du nord de l'Iraq, Beyrouth, pp. 124, 127

Keeney, J., \& Hickey, R. (2015). Using satellite image analysis for locating prehistoric archaeological sites in alaska's central brooks range. Journal of Archaeological Science: Reports, 3, 80-89. Retrieved from www.scopus.com

Lasaponara, R., Masini, N., Holmgren, R., \& Backe Forsberg, Y. (2012). Integration of aerial and satellite remote sensing for archaeological investigations: A case study of the etruscan site of san giovenale. Journal of Geophysics and Engineering, 9(4), S26-S39. Retrieved from www.scopus.com

Matoušková, E. - Hanzalová, K.: Documentation of geoglyphs on Nazca Plain, Peru using remotely sensed data. In Proceedings of the 23rd CIPA Symposium. Praha: ČVUT, Fakulta stavební, Katedra mapování a kartografie, 2011, p. 358-365. ISBN 978-80-01-04885-6.
Matoušková, E. - Hanzalová, K.: Documentation of geoglyphs in Peru Using VHR and SAR satellite data. In Proceedings of EARSeL Workshop Advances in Remote Sensing for Archaeology and Cultural Heritage Management. Gent: University of Gent, 2012, vol. 1, art. no. 1,

Matoušková, E. - Pavelka, K. - Starková, Lenka Nováček, Karel: $\quad$ DOCUMENTATION OF ARCHAEOLOGICAL SITES IN NORTHERN IRAQ USING REMOTE SENSING METHODS. In 25th International CIPA Symposium 2015 (XL-5/W7). Taipei: ISPRS, 2015, p. 331-336. ISSN 2194-9034.

Menze, B. H., \& Ur, J. A. (2012). Mapping patterns of longterm settlement in northern mesopotamia at a large scale. Proceedings of the National Academy of Sciences of the United States of America, 109(14), E778-E787. Retrieved from www.scopus.com

Mondino, E. B., Perotti, L., \& Piras, M. (2012). High resolution satellite images for archeological applications: The karima case study (nubia region, sudan). European Journal of Remote Sensing, 45(1), 243-259. Retrieved from www.scopus.com

Pavelka, K. - Bukovinský, M. - Svatušková, J. - Hanzalová, K.: Documentation of the Abadoned Town La Ciudad Perdida In Peru Combining of VHR Satellite and Terrestrial Mesurement. In Proceedings The 30th EARSeL Symposium. Paris: Earsel, 2010, p. 126-137. ISBN 978-3-00-033435-1.

Pavelka, K. - Matoušková, E.: From declassified satellite images to VHR data; temporal analysis of city growth. In Proceedings of 1st Workshop on Temporal Analysis of Satellite Images. Paris: Earsel, 2012, p. 150-158.

Pavelka, K. - Matoušková, E.: Combining Different Data Sources for City Growth Analysis and Architectural Heritage Mapping. In Monitoring and Modeling of Global Changes: A Geomatics Perspective. Dordrecht: Springer Netherlands, 2015, p. 37-62. ISSN 2198-0721. ISBN 978-94-017-9812-9.

Research Announcement: Free FORMOSAT-2 Satellite Imagery. CENTER FOR SPACE AND REMOTE SENSING RESEARCH, National Central University. Center for Space and Remote Sensing Research, National Central University [online]. Taiwan, 2014 [cit. 2014-10-09]. Available from: http://www.csrsr.ncu.edu.tw/FS2CFP/

Šedina, J. - Bílá, Z. - Housarová, E.: Archaeological survey by combination RPAS and geophysical methods. In 15th INTERNATIONAL MULTIDISCIPLINARY SCIENTIFIC GEOCONFERENCE SGEM 2015. Sofia: STEF92 Technology Ltd., 2015, vol. 1, p. 989-993. ISSN 1314-2704. ISBN 978619-7105-34-6

Šedina, J. - Pavelka, K. - Housarová, E.: RPAS as a tool for mapping and other special work. In Advances and Trends in Engineering Sciences and Technologies: Proceedings of the International Conference on Engineering Sciences and Technologies. Leiden: CRC Press/Balkema, 2016, p. 405-411. ISBN 9781138029071. 